\title{
Emergence of Resilience in the Context of Community Empowerment
}

\author{
Venkat Pulla $^{1, *}$,Bharath Bhushan Mamidi ${ }^{2}$ \\ ${ }^{1}$ Coordinator, Social Work Discipline, Australian Catholic University, Brisbane \\ ${ }^{2}$ Secretary of Centre for Action Research and People's Development, India \\ *Corresponding Author: Venkat.pulla@acu.edu.au
}

\begin{abstract}
In this chapter the authors sketch the contours of Community Empowerment, Resilience Development and in the context of modem day challenges of community empowerment The components of the process of coping and the process of resilience closely resemble. The difference being that resilience necessarily implies successful adaptation and coping does not Individuals who use multiple resources and are flexible and appropriate in their choice of coping strategies are more likely to adapt successfully. Successful adaptation in the context of individuals and communities enhances repertoire of personal and/or environmental resources, such as increased problem-solving skills, greater self-confidence or improved social relations. In the simplest possible terms community empowerment is a process by which people living in communities take charge of their lives. By which the authors imply that people declare ownership, indulge in actions that clearly include social and often political actions.
\end{abstract}

Keywords Empowerment, Resilience, Hope, Human Rights, Community Development

\section{Introduction}

The authors have a considerable shared past and present that includes working in Non-Government Organisations involving both paid and pro bono work and consulting years in community development in India and other Asian countries. The authors saw catalysts and facilitators in this process, working in communities as fellow travellers. These facilitators assisted communities to acquire ownership of resources and goods produced in the communities, and cope with a number of changes in the world. There were situations of dwindling care and security for human lives and property even then that required a belief that local communities' social and political actions are viable even with the push of globalisation. Building resilient communities and building communities of hope is essentially a way forward step. The author has lived over three decades of his life in a third world country, India where community services such as banks, schools, government services, postal services, primary medical services, micro credit for the poor, urban and rural basic services, seeds and agricultural extension all were put in place not always at right time and in right quantity. Yet they had an electrifying effect. Some simply were imitable. Boom prosperity and thrive appeared to be the key words. The growing social capital- sheer population and its pressure on land offered the keys.

In a western nation like Australia, with heavy drought devastations of the mid-nineties, similar community services began drying up. Several significant shifts in policies led to the closure of services and the transfer of government responsibility for the management of community services to the local communities. Serious under resourcing of communities resulting from economic and structural changes has undermined communities living and wellbeing. Gloom, survival and dwindling social capital meant more resigned and coping but more welfare dependent communities. The liberal conservatives of the last three decades dismantled the welfare states that arose in the mid twentieth century to protect nation's workers and their families. The result in some parts of the world is endemic: racist xenophobia, exacerbated by unemployment numbers and rising levels of poverty (Pulla, 2009). Ironically both the third world and what passes off as the first world saw communities feeling the powerlessness, anomie and adapting to 'learned helplessness' (Seligman, 2000). A large part of the world lives in proclaimed democracies where in dysfunctional economic and social inequities reign. These continue to provide agendas for most system dependent and system serving professions including social work where many seem to be tinkering, subsevering rather than contesting the root causes of the malaise. Inferior rights to a great majority of people in these nations and new forms of racism are also a big worry. When people feel, powerless, see and feel anomie, echo helplessness, professions such as social work need to recarve their agenda. The authors believe that this is happening much more in the current 
climate and it appears as though social work has withdrawn itself from its passion for community development at least this appears to be so in the western world. Crass individualism, economic rationalism, aggrandising globalism with little respect to localism seems to be at the nerve centre of this retrograde push to stay away from being, doing and thinking with communities. While individualism may seem to serve a few communities are gaining the profiles of powerlessness, central to which is the belief that they as communities are incapacitated. Intrinsic power that people have as repertoire of skills must be put to play to further beseech power. In the western world, soon to be followed by the rest of the world rural communities are being depleted as the aspiring young move to urban world leaving big dents and gaps in rural occupations. Ageing populations with fragile health living in in rural towns in isolation give you a picture of a sad vulnerable world. For instance in rural and remote Australia many elderly provide voluntary care to their frail aged families and neighbours.

\section{Power the Central Concept}

As practitioners, the authors see powerlessness as a form of power, proviso that there is tingling desire or a feeling that desires or asks for help. It is healthy to see 'communities in need' like a child that on demand must be provided the service or reasonably assisted to acquire a service. We stretch this analogy in the context of community empowerment to communities that have needs and that seek redress of their needs from councils, government departments and the ruling elites. Empowerment refers to the process by which people gain control over the factors and decisions that shape their lives (Labonte and Laverack, 2008). Itassumes that people are their own assets, and the role of the external agent is to catalyse, facilitate or accompany the community in acquiring power. 'Community empowerment', thus is a process for re-negotiating power to gain adequate control of resources within the community. It recognizes that if some people are going to be empowered, then others who have in plenty are sharing their existing power and giving some of it up. Power remains the central concept in all community empowerment activities directed at a range of themes i.e. economic development, health promotion, gender based development or cooperative agriculture or development of an ethnic community or minorities in any social context. The operative word is struggle and a struggle for gaining power.

Community empowerment necessarily addresses the social, cultural, political and economic determinants that underpin health, and seeks to build partnerships with other sectors in finding solutions. Viewed in the Indian context formal and informal institutions such as gram sabhas ${ }^{1}$, sanghams ${ }^{2}$, vana samrakshana samitis ${ }^{3}$ and self-help groups (SHGs) are central to myriad developmental processes for community empowerment Several nongovernmental organisations came into being to ensure that these processes and networks were utilised for both individual and collective good. The phenomenon of social capital and social network appeared to have provided the key components in many democratic societies including India. Communitarians seek to strengthen social capital and the institutions of civil society, through improvements in culture and economy. Both components are equally important to the profession of social work that espouses the values of social justice, human rights, human dignity and non-violent practice.

\section{Empowerment Case Study}

Commonly used explanations about resilience are hardiness, resourcefulness, and mental toughness, but it may be that a wiser way of looking at resilience is to see it as a dynamic process whereby individuals and communities exhibit positive behavioural alternation when one encounters major adversity, trauma, tragedy, threats, or even considerable sources of stress ( Pulla, 2013). It is different from innate strengths that individuals, groups and communities or entire populations possess regardless of the level of adversity they face. Under adversity, assets function differently (e.g. good forestry management practices results of inhabitants taking care - as illustrated below:

Garikabanda is a name of a small hamlet located at the foot hills along the embankment road from Chodavaram to Paderu in Visahapatnam district in Andhra Pradesh. Garikibanda is the gateway to Paderu the forest area. Untill 1997 it was known for its timber, oak and other precious wood smuggling. The rich natural resources were being slowly but systematically destroyed resulting in degradiation of the ecosystem. Depletion of natural resources further created unemployment in the Garibanda hamlets. The inhabitants were forced the degrade the forests further. Joint Forest Management, a strategy for resuscitation of degraded forests through people's participation was introduced and it virtually reversed the trend. The institution of Vana Samrakshana Samithi (VSS) has changed the way of life for these villagers. According to the villagers:

Recalling the past Appalakonda said.. .. 'The staff from 'Gramabhuyudaya (progress of village) a local NGO with the support from the Forest Range Officer (FRO) used to

1 Formally elected village councils

${ }^{2}$ Community organisations of beneficiary groups generally present in areas actively catalysed by NGOs.

3 Forest protection committees 
come regularly to our village and try to impress upon us on the protection of forests. But we gave a deaf ear to them saying that everyone talks but nobody can provide us livelihood. However, their repeated efforts made us to believe them slowly and finally we formed a Vana Samrakshana Samithi with 40 men and 37 women in 1997. So far we have treated about 50 hectares under this programme. Our journey from wood smuggling to forest conservation surprises us but we want everyone to learn from us".

The way our forests are growing:

Bhimaraju the VSS president proudly narrates the sequence of events undertaken by the VSS members for improving the forest growth. According to him:

- Wood smuggling, fire wood removal and charcoal making have been completely stopped.

- Soil and moisture conservation activities like contour trenches, check dams and stone terracing helped to recharge ground water resulting in improving the growth of vegetation and increased crop production.

- Almost 100 species of medicinal plants have surfaced and added economic value to the forests.

- Women have been given biogas units, smokeless stoves, leaf plate making machines and tamarind cake making machines etc. in order to remove the pressure on forests and enhance the livelihood opportunities (DO, 2011).

Clearly empowered communities build their resilience up many folds. Thus "resilience" is defined here as the ability to produce a social resistance through adaptation that produces the strengths within to fight the adversity and to withstand a crisis. Thus, in medium term it should produce the ability to fight back. The above case study illustrates the Joint Forest Management (JFM) model in India, based on the National Forest Policy - 1998, witnessed a transformation of power over forest resources with different actors engaged in negotiating and redefining the structure of power sharing between the forest dependent communities and the government over forests which were an exclusive area of the government with the inhabitants being viewed as 'encroachers '. The JFM model proposed sharing benefits with local communities in exchange for helping to protect the forests.

The JFM has been overwhelmingly successful programme (Nagnath. D'Silva., 2002) expanding to about 6000 villages from the original target of 2000 villages as the participatory approach to forest protection with certain entitlements to the community moved from Joint Forest Management in 1992 to Community Forest Management in 2002. 'Initially, there was lot of skepticism among the foresters about the worthiness of this strategy as a remedy for protection problems. As the approach for managing forests was new to the inhabitants of the forests that required efforts in the direction of community education and community development were needed to convince the people also about the assurances of the Government on the returns promised to the people, if they take up Joint Forest Management. However, with the passage of time, both the local people as well as the forest officials started seeing what JFM can do for rejuvenating degraded forests, and the concept gained more acceptance. The success stories spread from one village to another village (DO, 2011). Gradually the JFM expanded from coverage of degraded forests and sharing of NTFP to all standing forests, except forests which are inside a protected area (i.e. national parks or sanctuaries), The process of participatory forestry further expanded to 8300 villages with the state government mobilising financial resources from other sources.

Communities dependent on forest and sharing experiences of demanding control over forests had significant stakes in the JFM and also accomplished great successes in both regeneration of the degraded forests that provided additional incomes, directly and indirectly, and not only share of power over the forest but also freedom from the harassment by erring forest guards. End of the illegal extractions (mamools) and harassment is a major incentive and achievement, albeit not officially admitted, that may be seen as a latent function of the JFM (Bharath Bhushan, 1994).

In another instance, Adilabad forest areas have been experiencing a transformation. Adivasis (native inhabitants of the forests) who were considered encroachers and destroyers of forest took the responsibility of protection arid regeneration of reserve forest. Forest department that was to protect the forest from inhabitants by cordoning off areas decided to transfer the responsibility of forest protection and regeneration to the Adivasis. Forest officials who were used to extracting mamool (bribes) in exchange of forest wealth were required to acknowledge the customary rights of adiviasis and unlearning the practice of extracting bribes, abusing and arresting them for any petty issues. Their incomes through such mamools are institutionalized in regard to regular household requirements. Every household paid nine hundred rupees approximately 15 dollars' worth grains which are locally named as called Arakapatti and Porakapatti. In the experience of the second author the process of community empowerment and resilience in the recent times has also been facilitated by NGOs and their networks at district, regional and national levels. The interests and gains of different actors may not be similar and manifest. However, the convergence of interests based on outcomes of a latent nature is not less significant, as the JFM programme revealed. Outcomes of the participatory forestry included incentives for the villagers in the form of increased incomes, improved forest produce and freedom from harassment by the forest guards and for the department it is better protection of the forest cover. 


\section{Community Resilience}

Research in the area of resilience has identified five characteristics that describe resilient individuals: Being Positive, Focused, Flexible, Organized, and Proactive (Hoopes, Vargona, 2013) At any given time, each individual has a limited supply of attentional capacity and energy, which can be used as "adaptation resources"---the cognitive, physical, and emotional assets that enable a person to adapt when he or she encounters disruption. When such a supply is depleted increased levels of unproductive behaviours and reduced adaptations emerge. Resilience characteristics appear to enable individuals to use their adaptation resources more efficiently, both by conserving them from waste and increasing their available quantity (Hoopes, Vargoona, 2013). This can be extrapolated to provide a definition of community resilience as a community's ability, when it encounters or initiates major change, to achieve effective outcomes with minimal waste of resources. The two constructs are related but separate. While a community made up of resilient individuals will be better positioned to quickly and effectively adapt to change, a collection of resilient people may not necessarily mean that communities are able to respond to challenges in their environments. We also need to consider the effects of systems element to the equation.

Table 1. Community Resilience Descriptions

\begin{tabular}{|c|c|}
\hline Positive: External & $\begin{array}{c}\text { Recognition of community environment as challenge } \\
\text { and opportunity }\end{array}$ \\
\hline Positive: Internal & $\begin{array}{l}\text { Cultivation of strong internal resources that build } \\
\text { ability to capitalize on change }\end{array}$ \\
\hline Focused & $\begin{array}{l}\text { Goal centered behaviours appropriate to changing } \\
\text { circumstances }\end{array}$ \\
\hline Flexible: Internal & $\begin{array}{c}\text { Reconfiguration of structures and processes to meet } \\
\text { chan1res }\end{array}$ \\
\hline Flexible: External & $\begin{array}{c}\text { Draws resources outside the community to approach } \\
\text { change }\end{array}$ \\
\hline Organized & $\begin{array}{c}\text { Detection of patterns amid chaos; ordering complex } \\
\text { information }\end{array}$ \\
\hline Proactive & $\begin{array}{c}\text { Engaging change; willingness to take ambiguity and } \\
\text { experiment with new approaches }\end{array}$ \\
\hline
\end{tabular}

Every situation calling for transformation is unique and draws on resilience and transformational variables in different ways. Thus, each of the above resilience descriptions must exist in a dynamic balance to be optimally effective. For example, a strong emphasis on structuring information (Organised) may result in an overly rigid devotion or compliance to existing structures that interferes with seeking new and better ways to achieve goals (Flexible). The most resilient communities will have a well-rounded set of strengths to draw from, allowing them to succeed in any change endeavor.

Over the past twenty years, literature discussing the concept of resilience has emerged and "is now becoming a central paradigm in many disciplines, possibly replacing sustainability as the ultimate objective of development" (Institute of Development Studies, 2013). The concept of resilience provides a holistic view of the issues presenting and has the ability to create a degree of unity between and assistance in the integration of findings from a range of disciplines (Institute of Development Studies; McEntire, 2000 , p. 59). For instance, resilience in the context of disaster mitgation "to be fully effective it must be integrated into all sections of development and cover both measures to avoid disasters and measures to mitigate damage when they do occur" (United Nations, 2002, p. 47). Resilience therefore refers to "the ability to cope with climate change and natural disasters, in particular those associated with droughts, sea-level rise, increased temperatures and extreme weather events" (United Nations, 2002, p. 47). While this definition focuses exclusively on the physical environments stressors it is possible to see resilience broader than this. Whilst Engleman specifically mentions the need to adapt to changing climate and environments (United Nations, 2013, p. 16), political, social and emotional sources of change and stress also call for resilience and coping.

Resilience is seen to have an aspirational element as individuals and communities "face and manage ever-changing negative pressures and crises, preventing them, mitigate them, adjust to them, and adapt and thrive" (Oxfam International, 2013, p. 8). Resilience of communities, societies, organisations and nations is also affected by macro structural processes that produce patterns of relationships which have a bearing on the ways risks are shared by societies wherein disadvantaged communities, or even whole countries, bear the weight of another countries development because "power and wealth allow some people, corporations, and governments to mitigate the risks they face while directly or indirectly dumping those risks on people with far less capacity to cope" (Oxfam International, p. 4). Resilience of communities in such macro contexts also require abilities to ensure risks are distributed more equally among the nations and societies. The development of a common resilience methodology which includes a standard measurement has been recommended alongside an adaptive, flexible approach to resilience building with a respectable, bottom-up empowerment approach. Those at risk need to be included in discussions on resilience due to their possessed knowledge and views due to experience and expert advice may then be coupled with their aspirations (Oxfam International, 2013).

In the current days of turbulence, the ability of people, communities and the systems to maintain their 'core purpose integrity' (Zolli, and Healy, 2012) amid unforeseen shocks and surprises expects of us to adapt successfully in spite of experiencing risk factors. There are always challenges in this fragile world of ours, we have persistent poverty, increased susceptibilities to 
human disease and pestilence, climate changes and growing lack of paid employment that could possibly prevent poverty. While in the west equality, solidarity and social justice, true cornerstones of post-war welfare states are being replaced by inequality, exposing differences between 'us' and 'them', between natives and foreigners, rich and poor, those on top and those at the bottom (Pulla and Zidar, 2012) these differences are likely to grow further asking for more creative ways of ensuring a purpose of life and a life.

Reflecting back on earth quake in Latur, Maharashtra, in India, a country where there are no social security measures for people except some immediate relief measures, it was amazing to see how people bounce back to some form of normal routine. One of the lessons that the first author brought back to Australia from India was that most people in that Indian earthquake developed an identity of a survivor rather than a victim. Those stories that the first author heard about how they had a miraculous escape and about their inner spirituality that made them reach others allowed them to build stronger bonds after such traumatic experience spoke eloquently to one of the main elements in resilience, i.e. the context of culture. Pulla and Das (2014) in their paper on women headed households in Bangladesh floods indicate that the communities themselves are practicing preventions and do not expect the government agencies to come and cure and the fact that women in Bangladesh are able to take appropriate disaster prevention certainly is an indication that people developed resilience is definitely a cost-effective approach. Certain aspects of religions/spirituality may, hypothetically, promote or hinder certain psychological virtues that increase resilience. Research has established connection between spirituality and resilience. Indeed, there is a suggestion that modern western cultures have become neglectful of family and thereby reduce opportunities for children to acquire spirituality and resilience. Further, Benson and Thistlethwaite (2008), argue that Western culture and thus its communities have become focused on perfection and fail to view "pain, suffering, mistakes and failure" as normal components of life. Financial and personal successes are now valued and failure is not viewed as a learning experience that improves problem solving skills.

\section{Debating Resilience}

One resilience initiative which has been successful in many parts of the developing countries including Africa is micro-insurance. This move within Africa has created a way to manage environmental risk, provide options and create hope for the future within individuals, families and whole communities. Governments in the Philippines and Bangladesh have already begun efforts of resilience building. The local governments in the Philippines are legally obliged to dedicate $5 \%$ minimum "of regular revenue on disaster, reduction, preparedness and mitigation measures" (Oxfam International, 2013, p. 17). Such government schemes and initiatives are leading the way in this field and despite developed countries not yet dedicating generous funding; small steps have been created to begin building resilient communities.

In the developed world such as Australia has a high level of adaptive capacity and a stage to implement adaptive initiatives systematically and on a wide scale (Hennessy, et al., 2007). Climate change adaptations do not occur in silo, but as part of broadened societal development measures with Australia's current framework building understanding and adaptive capacity through actions which identify and fill knowledge gaps on one hand and reducing vulnerability in key sectors and regions for adaption (DCCEE, 2007). The Australian capability framework undertakes ongoing risk assessments to identify ecosystems and communities that are most vulnerable; conducts integrated assessments of the impacts of climate change on vulnerable communities (Hennessy, et al., 2007) and has agency to monitor effectiveness of policies and actions through evaluation of environmental effectiveness, cost effectiveness, distributional effects, including equity, and institutional feasibility (IPCC, 2007b). It is only after thorough identification of the most vulnerable, capacity building initiatives can be implemented. In the Australian context these programmes have been classified as:

- Resilience building programs,

- Personal awareness building social knowledge of climate change and its impacts,

- Community adaptive capacity education through the use of codes and standards, that measure environmental impacts, and social, ecological and economic studies,

- Mainstreaming climate change adaptation through the consideration of climate risks in all future decisions, ensuring the development of approaches to address any identified risks, and

- Having effective social systems, such as health, welfare and emergency response management, to deal with the impacts of climate change (DCCEE, 2011.

It is said that on an average, natural disasters cost the Australian community over $\$ 1$ billion per year, excluding death and injury costs. With climate change likely to increase the frequency of extreme weather events (DCCEE, 2007, p. 19) the following areas provide an opportunity for adaptation development:

- Predictive research regarding risk profiles of bushfires, flooding, cyclones, storm surges, and wind and hail damage.

- Development of natural disaster management risk reduction, emergency services planning, and recovery management with a focus on areas of increased vulnerability to extreme events.

- Community awareness education and training on disaster management through collaboration with 
emergency services (DCCEE, 2007).

- Vulnerabilities exist for the high concentration of people and infrastructure in urban areas as well as people living in remote communities. Therefore, the following adaptation practices may assist.

- Research to identify effective implementation actions in relation to planning, codes and standards and major infrastructure.

- Engage rural communities and industries dependent on natural resources in participatory research, communication and review.

- Development of resilience and coping ability within farmers regarding managing the circumstances of a changed climate system.

- Provision of information to farmers on how seasonality will alter due to climate change to support the agriculture industry to adapt.

- Strengthening the finance and insurance industries to help manage society's risk from weather related damages (DCCEE, 2007).

But certainly what has been mentioned above seems reasonable for application in other countries prone to disasters. Climate change places a gigantic burden on the disadvantaged and vulnerable and must be recognised as a crucial social justice issue therefore an area for community development and social work interventions. We are aware that adaptation plans that address equity issues will require a strong social safety net to be established to assist those who may otherwise have difficulty in adapting, i.e. vulnerable groups, such as the aged, and the rural poor communities.

\section{Conclusions}

Resilience, whilst building on vulnerabilities, does not necessarily eliminate or reduce the instances of disaster, crisis or breakdown and we suggest that this happens even in invulnerable development. Certainly this may not affect the number of disasters but it does increase the ability of the individual or community to bounce back afler or during the disaster as opposed to having a whole community go into shut down due to its inability to cope with the current crisis (McEntire, 2000).

The strengthening of the overall resilience of any particular group is dependent on factors such as culture and the level of marginalisation that the group faces. This critique applies across all sections of development, including sustainability, and is not limited to resilience models. Sensitive and holistic development assessments and practices are one way this may be managed.

Research claims that there is no direct relation between poverty reduction and well-being on one hand, and resilience building on the other. In fact people can be very resilient and very unwell (Pulla, 2013). Poverty reduction, for example does not necessarily arise out of a community's resilience in itself, although it creates an environment in which a community (or family) is more likely to recover from a trauma and is a protection and prevention measure of poverty, as opposed to an immediate solution. Equally it is said that resilience does not focus on challenging the structural inequalities (Oxfam International, 2013) However, as opposed to sustainability, it does focus on protecting individual and communal vulnerabilities as a means of prevention for such inequalities arising.

From the Indian experience of the implementation of forest preservation actions that were jointly undertaken by state and non-state actors and directly by the inhabitants of the forest we have further explained how empowered communities become resilient and move towards developing sustainable strategies. It is quite evident that empowerment and resilience have some commonalities but are not the same. That resilience has become central to the discourse on community environment and sustainability, is amplified in this paper.

\section{REFERENCES}

Abramson, L., Seligman, M. and Teasdale, D. (1978). Learned Helplessness in Humans: Critique and Reformulation. Journal of Abnormal Psychology. Vol. 87, No. 1 Q, pp. 49-74.

Bharath Bhushan, Mamidi (1994). A Step towards Regaining People's Control over Their Resources: A Study of Joint Forest Management in Adilabad, Sadbana, Hyderabad (Mimeograph).

Department of Climate Change and Energy Efficiency, (2007). National climate change adaptation framework, Retrieved 7 July 2012 from http://www.

coag.gov.au/coag_meeting_outcomes/2007-04-

13/docs/national_climate_change_adaption_frarnework. pdf

Labonte, R. and Laverack, G. (2008). Health promotion in action: from local to global empowerment, Palgrave Macmillan, London.

McEntire, D.A. (2000). Sustainability or invulnerable development? Proposals for the current shift in paradigms. Australian Journal of Emergency Management, Autumn 2000, 58--01.

Nagnath. B. and D'Silva. E. (2002). Bebroonguda: A Rare Success Story in Joint Forest Management, Economic and Political Weekly, Vol. XXXVII No. 06, February 09, 2002 http://www.epw.in/special-articles/bebroongudarare-success-story-joint-forest-management.html

Oxfarn International (2013). No Accident: Resilience and the Inequality of Risk. 172 Oxfarn Briefing Paper May 2013. Oxfarn GB.

Pulla, V. (2013). Coping and Resilience: People's innovative solutions. International Journal of Innovation, Creativity and Change, 1(1).

Pulla, V. and Das, T. (2015). Coping and Resilience: Women headed households in Bangladesh, in Venkat Pulla, Bharath Bhushan Mamidi, (eds) Some Aspects of Community Empowerment and Resilience, pp. 228- 242), Allied Publishers, Delhi.

Pulla, V. and Zidar, R. (2012). Unpaid labour in Slovenian Society: A case for Mental Health Social Work Approach, in Pulla, V., 
Chenoweth, L., Francis, A. and Bakaj, S., in Papers in Strengths Based Practice, pp. 75-93, Allied Publishers, New Delhi.

Vargona, L. and Hoopes, L. (2013). The community resilience profile: a framework for assessing community development efforts in Pulla, V., Shatte, A., Warren, S. (Eds.), Perspectives on Coping and Resilience, pp. 307-333, Authors Press, New Delhi. 